\title{
RECOMMENDATIONS FOR HOW TO RESPOND WHEN THE FAMILY IS HOPING FOR A MIRACLE
}

\author{
Author: John Stonestreet, PhD, MDiv
}

Johns Hopkins All Children's Hospital, Spiritual Care and Chaplaincy, St. Petersburg, FL, USA

Hopecare, Inc., Executive, Clearwater, FL, USA

john@hopecare.com

Author John Stonestreet discloses conflict of interest as the founder of HOPECARE, INC. (www.hopecare.com)

\section{ABSTRACT}

Objective: To recommend how physicians can best respond to families whose hopes for a miracle via divine intervention influence their medical decisions, like, for example, making them not want to withdraw ventilatory support in cases of poor neurologic prognosis because they are still hoping for God to intervene.

Methods: Auto-ethnographic analysis of chaplaincy experience in this clinical context yields a nuanced 90-second, point-of-care spiritual intervention physicians can use to address the religious aspect of families who base medical decisions on their hopes for a miracle via divine intervention. Explanation of how spiritual intervention dovetails with existing physician communication protocol for responding to families hoping for a miracle.

Results: Spiritual intervention for religious aspect of miracle-hoping families is integrated into existing physician communication protocol for responding to families hoping for a miracle with recommendations for utilization of existing communication technology when necessary.

Conclusion: Properly addressing the religious dimension of families hoping for a miracle may be helpful for physicians interested in decreasing their own stress levels, improving outcomes for this clinical context, and ensuring that unintentional discrimination does not perpetuate racial disparities in end-of-life care.

Keywords: Poor prognosis, medically non-beneficial care, futility, breaking bad news, withdrawal of care, miracle, hope, goals of care, communication, health disparities, racial discrimination, ethnocultural discrimination

\section{INTRODUCTION}

The award-winning short documentary film, Extremis (1), follows Dr. Jessica Zitter and her team through the intensive care unit (ICU) at Highland Hospital in Oakland, California as they seek to 
help families make medical decisions for their loved ones facing death. While Dr. Zitter originally set out to "be a hero" by "rescuing patients from the brink of death" (2), she was eventually forced to face the sad reality that when death is inevitable, blind medical heroism is anything but heroic. Dr. Zitter shares her epiphany through the following anecdote:

When I was a young attending I had been asked to put a large catheter in someone's neck. She was dying. And I went into lifesaving mode. Right before we were getting ready, I looked up and I saw this nurse in the doorway, and she looked at me locking eyes with me and said, 'Call the police. They're torturing a patient in the ICU.' My heart dropped into my stomach, and I realized, “Oh, my gosh, she's right. What I'm doing right now is not gonna help her. It's not gonna get rid of this disease that's killing her. And I don't wanna do that anymore (1).

While she still rescues patients from the brink of death, Zitter is now equally passionate about rescuing the dying from an unnecessarily drawn out, medicalized death that they may not have wanted. In the ICU environment, this often involves securing the family's agreement to turn off the ventilator that is breathing for the patient and allow nature to take its course. That is a difficult decision for many families to make. As the documentary conveys, it is especially difficult when the family is hoping for a miracle by divine intervention.

This hope in God for another sort of miracle when medicine has reached the end of its own miracle promises is perhaps one of the most challenging issues for physicians to negotiate with the families of dying patients. What is the physician to say?

Speaking to the brothers of a dying African American patient named Selena, Dr. Zitter invites them into her world by sharing how painful the situation is for her as a physician:

Every day people with very poor neurologic prognoses are attached permanently to machines, and, unfortunately, it's very hard, emotionally, for us physicians when we feel that we're taking a body and we're just keeping it alive when it's not really the person (1).

After hearing how his sister's subsistence on a breathing machine is affecting Dr. Zitter, one of Selena's brothers responds by returning the favor of vulnerability and invites Dr. Zitter into his world:

"But God has proven to me, miracles are miracles, and we're askin' him for one" (1).

Selena's brother was not the only member of this African American family hoping for a miracle. Dr. Zitter has a similar conversation with Selena's daughter who, like her uncle, is hoping for a miracle: "To me the whole situation is miraculous...so I'm always looking for another miracle" (1).

Meeting Selena's daughter on her own terms, Dr. Zitter assures her that the whole medical team is also hoping for a miracle. But Selena's daughter doesn't seem convinced.

Despite all her best efforts, Dr. Zitter's conversation with Selena's brothers and daughter still seems strained. It is almost as if Dr. Zitter is holding one end of a rope and Selena's brothers and 
daughter are holding the opposite end. In both of these conversations, Dr. Zitter seems to be doing everything she can to connect authentically with this family in sincerity. She is vulnerable and transparent about her own moral distress over artificially extending death, and she even meets them on their own terms by affirming their hope for a miracle. But somehow, the two parties still seem engaged in a tension-filled tug-of-war. Unfortunately, when healthcare decision making turns into a tug-of-war between physician and family, neither side wins.

In the case of Dr. Zitter and Selina's family, the documentary ends by stating that "Selena was surgically attached to the breathing machine" where she "regained periods of consciousness before passing away six months later" (1). What may be more regrettable than the medical outcome (which is still subject to interpretation) is the lack of a therapeutic connection between doctor and family who, despite Dr. Zitter's valiant efforts, still seem like trains passing in the night. Is there anything more Dr. Zitter could have said or done to change the tenor of the conversation?

When medical science intersects with non-medical issues like patient/family religious beliefs, how are physicians to navigate these murky waters?

As a hospital chaplain, I have never been in a physician's position to make a medical case for a family to consider removing a ventilator and allowing a more natural death. However, countless families have asked me to pray for healing regardless of the odds, and I wonder if my journey of learning to pray for the impossible may shed some light on physician communication in this challenging context.

Although a number of years have passed, I can still remember the first time I was asked to pray for a miracle in my chaplaincy internship at Duke University Hospital. That simple request was deeply troubling to me. I felt tremendous anxiety. I didn't have clarity on exactly why it was such a challenge in that moment, but I just knew that I felt a tremendous ambivalence about how to respond.

I remember doing a joint visit in the ICU with a divinity school student who didn't seem to share my ambivalence. While we were there, parents of a young man with late stage terminal cancer asked her to pray for a miracle, and she didn't seem to have any of that hesitation or anxiety/ambivalence that I felt; she just launched right in to a passionate, wholehearted prayer for their miracle. A part of me was jealous of her ability to respond so readily and sincerely. If the gold standard of health communication is person-centered care, wasn't that precisely what she was providing in that moment? There the parents were hoping in God for the impossible, and there she was, right with them, praying for that very miracle. A part of me thought, "Wow! That's beautiful. Nothing is holding her back from being with them right where they are."

Another part of me felt just the opposite; that part of me felt deeply cynical. I can still recall some of the words of her prayer. She said: "And God we just ask you to do what you do best, and that is provide health and healing! And we thank you in advance for what you will do and for what you are doing in this very moment!" I remember feeling a deep cynicism at that moment, thinking, "Well, if that's what God does best, then he's doing a really bad job here at Duke Hospital! He's either lazy, or he's unmotivated, or he just doesn't care, because people are praying for miracles and dying in here left and right." 
My divinity school colleague's presumptive prayer made me not only cynical but morally distressed. I wanted to ask, "Wait a second, what is it that we are promising here, and how can we just make a declaration like that and waltz out of this hospital room as if everything's going to be fine?" As if we know our prayer had been meaningful in the way that it was intended. On the contrary, we know that in most cases in these situations, God does not do what we just said he does best. I continued to be bothered by that experience, as I struggled to reconcile my admiration with my cynicism and moral distress. It seemed to me that there was something so right and something so wrong about that prayer.

While perhaps under-represented in $21^{\text {st }}$ century hospitals, my divinity school colleague was not alone in approaching prayer for unlikely outcomes with a disconcerting assumption of their likelihood. Furniss (3) articulated a similar approach. Working as a hospital chaplain at the time, Furniss counseled patients to pray once for their own physical healing, and then revert to "giving thanks in faith for the [physical] healing that is [already] happening" since "Jesus says, "Ask and you shall receive" (3). Furniss did qualify his recommendations for healing prayer, conceding that, "Where advanced age is present or the will to live is gone, I do not think it is necessary for us to engage in healing prayer" (3).

But, what is the threshold for "advanced age?" And what does this mean for cases where advanced age is not present or the will to live is not gone? Are we to assume that earnest prayer will usually overcome terminal illness for the young and/or hopeful? As a chaplain who sees death on a regular basis at a pediatric hospital, it is an understatement to say that I would not feel comfortable counseling children and families facing a grim prognosis that they should simply pray for physical healing and then assume a successful outcome. ${ }^{1}$ Jesus himself prayed "let this cup pass from me" but he did not conclude the prayer with an assumption that the cup was already passing, and indeed...the cup did not pass.

Returning to my early recollection of peer responses to families hoping for a miracle, I remember another occasion that made a lasting impression on me. One of my chaplain-in-training colleagues shared in group/class that he was asked to pray for a miracle earlier that day in a case where a wife and daughter did not want to let go of their dying 72-year-old husband/father with multiple co-morbidities. My colleague reported that he had to tell the family that praying for miracles wasn't something he could do because it didn't fit with his beliefs. Instead, he offered to journey with them in their suffering and help them to prepare for a good death.

Once again, I experienced a story about prayer for miraculous healing with ambivalence. But this time, a part of me really admired my colleague for facing the most likely reality of their situation, being honest about it, and being willing and able to walk down that path with them. At the same time, another part of me was deeply saddened. If our goal is person-centered care, my colleague had provided the opposite. A family had asked him from the depths of their heart for what they most yearned for, but he dismissed their request as something too incompatible with his beliefs. It seemed to me then - and seems to me still— that the family's request should not be so quickly dismissed. How could he just opt out of meeting people where they were and bringing their hopes to God? His inability to do that made me wonder if they felt comfortable enough with

\footnotetext{
${ }^{1}$ But I would honor their faith perspective if that was their theology.
} 
him to consider his counter-offer. Even if they had at least appeared to accept it, could their acceptance have been genuine?

My chaplain colleague was not alone in rejecting a family's request to pray for a miracle. Jones (4) relates a similar experience from his early chaplaincy days. Jones tells the story of being asked by grief-stricken parents to pray for a miracle for their young daughter who was dying in a pediatric ICU:

A prayer was all that they had left, just a simple prayer for a miracle that their daughter would be healed and live. It was not too much to ask.

But I could not pray for healing that night.

See, I knew too much; or at least I thought I did at the time (4).

At the time, Jones saw the family's hope for an unlikely miracle as an intellectual impasse. But in hindsight, Jones sees his inability to petition God for the parents' request as a form of emotional avoidance on his part:

I could have prayed for a lot of things that night, but not for healing. It was better and safer to be theologically correct than to feel the depths of all the pain. It was easier to be theologically rigid than to admit to my helplessness. I was more interested in helping the parents through their denial and on toward acceptance. I knew my Kübler-Ross. I was learning clinical theory. My theology and interventional theory may have been right, but they were everso empty (4).

Jones summarizes his emotional shortcoming as a failure of compassion.

Not long ago, I found a journal entry from the time period when I was contemplating the two extremes I had observed in my colleagues and trying to pinpoint where I fit on the spectrum constituted by their divergent approaches. Several other chaplains I spoke with shared one or the other of their perspectives or offered approaches that I also found unsatisfactory. One said that he felt pressure from the medical team to "deal with" these people, but he had no idea how to respond. Another said that she had developed language that allowed her to sound like she was praying for a miracle, even though that's not really what she was praying for, so that she could appease people without offending them. That approach felt disingenuous to me.

Agonizing about where I stood on the spectrum of responses I had observed, especially in light of my relatively recent conversion to Eastern Orthodoxy, I found myself praying my way into a particular prayer that synthesized pieces I admired about what I observed and what I struggled with in those two initial divergent approaches. One of my colleagues fully joined with the family in their hopes for the impossible. My other colleague fully faced the painful reality that the family was likely to encounter and offered to walk that difficult path with them. In both approaches, I saw a valiant response to a communication challenge, and I sought to somehow appropriate the good I saw in each approach.

In hindsight, what I think I struggled with in each response was its seeming need for an air of certainty that made me feel uncomfortable given the profound uncertainty characterized by the divergence between hope and expectation that seemed to define the situation. One response embraced the family's hopes with what felt like an unrealistic air of positive certainty, and the other response rejected the family's hopes with what seemed like an authoritarian air of negative 
certainty. I found myself struggling to communicatively embrace the family in their divergence of hope and expectation with a feebleness of uncertainty that aligned with what I experienced as the reality of their situation.

Like my divinity school colleague, I endeavored to whole-heartedly enter into the family's hopes for a miracle, no matter how unlikely, and partner with them in bringing that request to God in earnest. At first, this was not easy, but it still felt right. I think part of my challenge was a battle between my heart and my head. We tell ourselves intellectually that it isn't fair to the family to fan the flames of false hope, as if we are incapable of creative, nuanced, and transparent communication. But I wonder if that isn't our own excuse for not wanting to enter into that helpless space of painfully divergent hopes and expectations with them. True communicative joining is painful; it requires "com"-"passion" where "com" means "with" and "passion" means "suffering." Suffering with and being with suffering. As Jones confessed above, it "was better and safer" and "easier" to be "correct" and "rigid" and hold the family at arm's length by refusing to pray for a miracle rather than to "feel the depths of all the pain" and to "admit my helplessness," which are prerequisites for joining them in crying out to God for the impossible.

Over time, I became surprisingly comfortable with suspending my calculations, embracing uncertainty, and trying to fully join the family in their hopes and offer those hopes up to God together with them. I found deep meaning in being with them right there in that space. And instead of wondering what kind of unrealistic expectations I may be creating by joining with them in their hopes, I harnessed the honesty and transparency that I admired in my chaplaincy training colleague who couldn't bring himself to pray for a miracle, and I deliberately faced the uncertainty of the situation in the prayer itself rather than wrapping a neat little assumptive bow around everything and ending the prayer triumphantly, or even expectantly, as if the miracle was a forgone conclusion. For example, I named the reality that, far from assumptively claiming a positive outcome, what we are really doing in praying for a miracle is simply crying out to God as little children do to their parents, "lifting up" our hopes and cares and desires without calculation or pretense, and "laying them down at [his] feet" (5). In praying for a little child to overcome a destructive brain tumor, I became a little child too and joined together with her parents as fellow children before the almighty God, lifting up their hopes with feebleness and fragility.

As a further effort to sincerely honor hope without creating false expectation, in addition to naming our child-like posture in prayer, I began to even more directly acknowledge the uncertainty of the situation in the prayer itself. In praying for a 58-year-old woman waiting in the transplant queue, troubled by the paradox that in hoping for a healthy heart to become available for her, she was effectively hoping for another healthy person to tragically die, I transparently named the uncertainty and ambivalence of the situation in the prayer, praying, "We have no idea what happens when we pray this prayer" (5). Rather than ending with the focus on uncertainty or some false assertion of certainty about the corporeal, I ended these prayers with a focus on what we can know through spiritual experience - that God is always near to us, knowing our torment, and taking our torment into his heart; he was in the room, together with us, suffering with us and loving us. And even when God allows death, we can still affirm that death is not only an end to life on this earth; death is also a new beginning for eternal life in the presence of God. 
Finding my way to this prayer transformed my experience of prayer requests for miraculous recovery from utter terror to deep meaning. I felt that closeness that I was jealous of in the divinity student's prayer, that feeling of being right there with the family. But I felt no concern about creating false expectations. Acknowledging the reality of uncertainty achieved the intellectual honesty that I respected in my other chaplain colleague. I was able to enter authentically into the family's journey, to take this journey together. I sincerely hoped for their miracle. But if (as was most likely) the miracle was not to be, we could continue to express both our hopes and uncertainties and discover meaning together along the way.

Prayer that acknowledged the family's heartfelt desire, the reality of uncertainty, and the certain presence of God's loving embrace in this moment brought tremendous meaning to an otherwise desperate, impossible situation. I went from a sort of torture to deep joy in these encounters. And I noticed at the end of these prayers that there was often an emotional release. Even when the tears were accompanied by silence, those tears seemed to signify that permission was granted to hold on to hopes, and acknowledge fears, and feel pain all at once rather than having to choose just one emotion in exclusion of the others. In bringing all of these raw emotions to God, as the Psalmist did, there is a sort of naked authenticity that brings peace. Another thing I noticed was that, in situations where different members of the family disagreed on whether or not to remove the ventilator and whether or not to hope in God for a miracle, both parties would come to me individually and thank me for the prayer, saying that it was exactly what was needed. Here, too, there was a coming together in hope and uncertainty rather than taking sides.

This experience of feuding family members coming together over prayer makes me wonder if the kind of nuanced prayer I developed may be useful for physicians conducting "goals of care" conversations with families who are hoping for a miracle through divine intervention. What are the key takeaways from chaplaincy experience in this context, and how might they apply to physician communication?

The first obvious lesson begins with a simple acknowledgement that responding to families hoping against all odds for a miracle via divine intervention is a complex communication challenge that requires a thoughtful, intentional response. While the challenge is real, it is also surmountable through caring, creative, and transparent communication. In sharing my story, I do not claim to offer an unprecedented spiritual intervention. I am certainly not the first chaplain to deepen my embrace of uncertainty and capacity for compassion by discovering that it is possible to sincerely hope and pray for the impossible while still facing the reality that it is unlikely. Gardner's account (6) of "A day in the life of a Mayo chaplain" is evidence enough that my general conclusions, while perhaps not the same as every other chaplain who has struggled in this context, are not unique to me. Gardner's description of her practice includes both an earnest ${ }^{2}$ prayer for miracles and a clearly articulated embrace of uncertainty, naming the difference between a hope/prayer and a promise.

The second lesson learned from chaplaincy experience is that thinking you know too much to compassionately engage another's hopes may be an intellectual ruse concealing emotional

\footnotetext{
${ }^{2}$ I can only assume
} 
avoidance. While this communication challenge can first mask itself as an intellectual impasse, ${ }^{3}$ it has the potential to unfold into an emotional opportunity for a clinician to discover within $\mathrm{him} /$ herself a deeper level of compassionate communication in this critical healthcare context. ${ }^{4}$

If the ruse of an intellectual impasse can get in the way of a breakthrough in compassionate communication for healthcare chaplains, how much more for physicians who are seldom heavily trained in the emotional dynamics of communication?

But why are we turning the focus to physicians? Isn't this properly the chaplains' domain? Yes and no. While the spiritual realm may technically be the chaplains' domain, it is important to remember the clinical reality that it is the physicians who face the communication challenge created by the conflict between miracle hopes and medical limitations more often and more directly than anyone else. Because "goals of care" conversations unavoidably revolve around complex medical science, it is the physicians who spearhead these conversations. And because the purpose of this health communication is to discern the proper "goals of care," it is the physicians who encounter head-on the families whose medical decisions are influenced by their hopes for a miracle through divine intervention.

When a family's hope for a miracle colors their response to a terminal prognosis and makes them resistant to physician recommendations for the withdrawal of aggressive measures, might prayer in that moment be helpful? Because I am suggesting a "point-of-care" prayer offered by the physician as part of the "goals of care" conversation, obvious challenges to this possibility come to mind. What if, as is often the case with so few chaplains in the hospital, no chaplain is present at that moment? Many physicians, regardless of their spiritual commitments, wouldn't feel comfortable performing the prayer, even if they were given a text to read. This is a serious issue that would have to be worked out, but the advance of modern medicine is never halted by a challenge. Could communication technology be used to bridge this gap?

In raising the issue of physician-provided prayer, I am only marginally building upon a physician communication protocol already in existence. Thomas J. Smith, MD, Director of Palliative Medicine and Professor of Oncology at Johns Hopkins, in partnership with a chaplain, nurse, and physician colleague, proposed a communication protocol for clinicians to use in response to families hoping for a miracle when confronted with the limits of medical intervention to prolong life (7). The "AMEN' protocol" is an acronym that stands for "affirm, meet, educate, no matter what." Here is the protocol in brief:

- Affirm the patient's belief. Validate his or her position: "Ms. X, I am hopeful, too."

- Meet the patient or family member where they are: "I join you in hoping (or praying) for a miracle."

- Educate from your role as a medical provider: "And I want to speak to you about some medical issues."

- No matter what; assure the patient and family you are committed to them: "No matter

\footnotetext{
${ }^{3}$ Recall Jones' words above: "See I knew too much; or at least I thought I did at the time."

${ }^{4}$ In hindsight, Jones specifically states, "All I needed was compassion." While traveling a different route (I never denied the prayer as Jones did) I came to a similar conclusion about compassion being the key to moving from my head to my heart.
} 
what happens, I will be with you every step of the way" (7).

The first two steps of the protocol, "A" = "Affirm" and "M" = "Meet", come together to enact the vital process of "joining" that I referenced above in my personal story of learning to pray for miracles. One of Smith's co-authors, Cooper, shared with cancertherapyadvisor.com that a goal of the protocol is to communicatively empower the provider "to join [emphasis added] the patient or family member as a fellow human being with hopes and aspirations" which can build "a sense of trust and commitment to care." (8)

Also key in the protocol is the use of the word "and" instead of the word "but" in the "E" = "Educate" part of "AMEN", as a transition from joining to educating. Smith et al. stress that when physicians use of the word "but" instead of the word "and," they "unintentionally place themselves in direct competition with the God of the patient's or family's understanding" (7). So if the physician says, "I join with you in hoping (or praying) for a miracle, but I want to speak to you about some medical issues," they are diminishing their previous efforts at joining by introducing a spirit of competition. Thus the recommendation to replace "but" with "and," stating, "I join with you in hoping (or praying) for a miracle, and I want to speak to you about some medical issues."

I know this is not the intention of the authors, but for the patient/family involved, I wonder if the AMEN protocol in its current form might sometimes feel more like the physician is giving a nod to joining rather than actually joining. I agree that transitioning with "and" rather than "but" definitely sounds less contentious. But if the goal of transitioning with "and" rather than "but" is to preserve a spirit of unity and prevent a spirit of disputation, is the swapping out of this one word really enough to prevent families from perceiving a transition from joining to debating?

I believe the AMEN protocol is a giant step forward for providers communicating with families hoping for a miracle against all odds. Nevertheless, I wonder if simply stating, "I join you in hoping (or praying) for a miracle" before transitioning with "and I want to speak to you about some medical issues" accomplishes the stated goal of truly joining with suffering families and walking with them "every step of the way" (7). What I fear is that, at least for some families, the "and" becomes a functional "but" when we give lip service to joining in hope or prayer without offering to communicatively perform that promise.

I would like to suggest that the AMEN protocol might by augmented through the embodiment of the "Affirm" and "Meet" steps if the physician offered to provide and stay respectfully present for, a point-of-care, third-party prayer. If a chaplain who is comfortable praying sincerely for miracles is already present in the room or readily available, that would be ideal. Otherwise, out of necessity, one could resort to communication technology, as is already done for language translation in the case of Remote Video Interpreting (RVI). Regardless of their language of preference, it is common for physicians to work through a third party to communicate with families in their own language. Similarly, ${ }^{5}$ regardless of their beliefs, the physician can honor the

\footnotetext{
${ }^{5}$ This analogy between remote, third-party, point-of-care, intercessory prayer and Remote Video Interpreting may be even stronger than it first appears. A Harvard physician and scholar (9) reported that religious beliefs statistically accounted for disparities between blacks and whites in end-of-life healthcare preferences and medical decisions. Showing what Balboni and Balboni (9) might call hospitality to patient/family religious beliefs, therefore,
} 
family's suffering by staying respectfully present for a momentary prayer in hope that the family will benefit from their emotional support.

A review of palliative care issues identified by patients emphasizes the importance of religious support for African American patients and stresses that patient needs should dictate suitable interventions (10). While palliative specialists deliver specialty palliative care, this intervention falls under the umbrella of primary palliative care, which is also the responsibility of nonpalliative specialists. In short, if the "AMEN" communication protocol for providers responding to miracle-hoping families included an actual "amen," I believe, as the old church saying goes, "all God's people [would say] 'Amen."”

A closing anecdote: Several years ago, after delivering a presentation on the paradox of "false hope" at an academic medical center, I was approached afterwards by a palliative care social worker who relayed a salient story. The previous week, she recalled debriefing with a physician who vented his frustration coming out of a "goals of care" conversation, stating with notable dismay, "the family is just fixated on their miracle." When the medical team later returned for their next conversation with the family, the social worker brought the chaplain along and began the conversation by asking the chaplain to offer a prayer. Immediately after the prayer, the family raised their gaze to meet the physician and, to his great surprise, expressed their readiness to withdraw the ventilator. "All they wanted," exclaimed the social worker, "was a prayer."

What may first seem like an irreconcilable conflict between science and religion does not need to be reduced to an exclusively intellectual impasse. I believe that caring communication can transform seemingly irreconcilable differences into surprisingly meaningful alliances. This does not mean that prayer will always produce a magical agreement between the physician and the family on the proper goals of care. Nevertheless, is there any harm in replacing emotional avoidance with compassionate communication and seeing where it might lead?

\footnotetext{
is respecting both their culture and, in many cases, their ethnicity. Like providing language interpretation services, it may be yet another form of speaking their language. Perhaps it is no accident that the documentary video scenes referenced in the introduction to this article depicted a white doctor struggling to speak a black family's spiritual language. Is our present, prevalent failure to provide point-of-care intercessory prayer for families hoping for a miracle an unintentional form of racial and ethnocultural discrimination?
} 


\section{References}

1. Krauss, D. Extremis [Video file]. Retrieved from http://www.netflix.com; (2016).

2. Zitter J N. Extreme Measures: Finding a Better Path to the End of Life, New York: Penguin; 2017.

3. Furniss G M. Healing prayer and pastoral care. Journal of Pastoral Care and Counseling 1984;38:107-119.

4. Jones L C. A prayer for healing denied. Journal of Pastoral Care and Counseling 2014; $38: 1$.

5. Stonestreet, J. A prayer. US Copyright Office 2009;1.

6. Gardner L. A day in the life of a Mayo chaplain .... Journal of Pastoral Care \& Counseling 2017;71(4):293-294.

7. Smith TJ, Cooper RS, Ferguson A, Bodurtha, JN. AMEN in challenging conversations: bridging the gaps between faith, hope, and medicine. Journal of Oncology Practice 2014;10(4):e191-e195.

8. Burgess L. AMEN protocol designed to help clinicians when patients hope for miracles. In: Cancer Therapy Advisor [online]. Available at: https://www.cancertherapyadvisor.com/general-oncology/amen-protocol-designed-tohelp-clinicians-when-patients-hope-for-miracles/article/364943/. Accessed March 28, 2017.

9. Balboni MJ, Balboni TA. Hostility to Hospitality: Spirituality and Professional Socialization within Medicine, New York: Oxford University Press; 2019.

10. Busolo, D, Woodgate, R. Palliative care experiences of adult cancer patients from ethnocultural groups: a qualitative systematic review protocol. JBI Database of Systematic Reviews and Implementation Reports 2015:13(1):99-111. 